This is an electronic reprint of the original article. This reprint may differ from the original in pagination and typographic detail.

Author(s): Lehtomäki, Elina; Janhonen-Abruquah, Hille; Tuomi, Margaret; Posti-Ahokas, Hanna; Okkolin, Mari-Anne; Palojoki, Päivi

Title: Research to engage voices on the ground in educational development

Year: $\quad 2014$

Version:

Please cite the original version:

Lehtomäki, E., Janhonen-Abruquah, H., Tuomi, M., Posti-Ahokas, H., Okkolin, M.-A., \& Palojoki, P. (2014). Research to engage voices on the ground in educational development. International Journal of Educational Development, 35(March 2014), 37-43. https://doi.org/10.1016/j.ijedudev.2013.01.003

All material supplied via JYX is protected by copyright and other intellectual property rights, and duplication or sale of all or part of any of the repository collections is not permitted, except that material may be duplicated by you for your research use or educational purposes in electronic or print form. You must obtain permission for any other use. Electronic or print copies may not be offered, whether for sale or otherwise to anyone who is not an authorised user. 


\title{
Research to engage voices on the ground in educational development
}

Lehtomäki Elina ${ }^{1}$, Janhonen-Abruquah Hille ${ }^{2}$, Tuomi Margaret $\mathrm{T}^{3}$., Okkolin Mari-Anne ${ }^{3}$, PostiAhokas Hanna $^{2}$, Palojoki Päivi ${ }^{2}$

\begin{abstract}
This paper discusses how a variety of qualitative methods could be used for investigating the engagement of the voices on the ground, where the change is expected to happen. It also reviews how qualitative research approaches involve students and teachers, the so-called "target groups" of educational development, as subjects, rather than objects. The qualitative methods are presented here for their potential in engaging the voices on the ground. Actor-centred inquiry and participatory action research consist of data collected, analysed and reported, in collaboration between researchers and the research subjects. Enabling the subjects as autonomous actors to take part in the analysis of their own learning and education provides a means to bring deeper cultural and social knowledge into the development processes. In this way research may promote ownership of educational development. Furthermore, the actors' voices are key factors in the re-definition of global, national and local educational development targets for the EFA beyond 2015.
\end{abstract}

Keywords: qualitative research, actor-centred methods, participatory action research, educational development, Education For All

\section{Introduction}

National education policies and international cooperation are guided by international benchmarks such as the global Education For All (EFA) targets and the Millennium Development Goals (MDGs). While the set goals are both quantitative and qualitative, achievements are monitored quantitatively. What is defined as evidence of change must be broadened and deepened (Little and Green, 2009; McGrath, 2010; 2013; Okkolin et al., 2010). Qualitative analysis can add to this picture and the research approaches presented in this paper may be the complementary partners for mixed-methods to strengthen the role of research in educational development.

In education, as in social sciences in general, the trend is towards complementary views and multidimensional research. Existing research underlines that our knowledge of the complexity in educational development is still limited (see Amundsen and Wilson, 2012; McGrath, 2010) and contextualization of education is needed. Conducting research can promote sensitivity and respect for the stakeholders on the ground (Crossley, 2008; Crossley and Watson 2011). Sensitivity in the use of research findings must also be taken into consideration (Christians, 2005; Foster et al., 2012; Preece, 2013). This paper reaches beyond sensitivity to cultures and contexts by discussing how qualitative methods can be used for investigating the engagement of voices on the ground, the place

\footnotetext{
${ }^{1}$ University of Jyväskylä, Finland, elina.k.lehtomaki@jyu.fi (corresponding author)

${ }^{2}$ University of Helsinki, Finland, hille.janhonen-abruquah@helsinki.fi, hannapostiahokas@imap.cc, paivi.palojoki@helsinki.fi

${ }^{3}$ University of Jyväskylä, Finland, margaret.tuomi@jyu.fi, mari-anne.l.okkolin@jyu.fi
} 
where change is expected to happen. It also reviews how qualitative research approaches can involve students and teachers, the so-called target groups of educational development, as subjects, rather than objects, thereby enabling subjects, as autonomous actors, to take part in the analysis of their own learning and education. This approach provides a means to bring deeper cultural and social knowledge into the development process and promotes the ownership of educational development at the national and local beginnings.

The qualitative methods are presented here for their potential in engaging the voices on the ground. Actor-centred inquiry and participatory action research consist of data collected, analysed and reported, in collaboration between researchers and the research subjects. The actor-centred methods reviewed are empathy-based stories, visual methods and the voice-centred relational method. The two participatory action research types are consultation and the communicative engagement methods. They employ the collaboration of stakeholders in the whole research process to assess and analyse challenges to unravel complicated problems and strive for new solutions. These research methods aim to obtain both objective knowledge and subjective interpretations of participants' views for promoting change to improve their lives and, in this case, their education and the education of others. Thus, these methodologies may challenge traditional views in planning and monitoring educational progress.

\section{Characteristics of the actor-centred and participatory action research methods presented}

Three types of actor-centred approaches and two types of actions research methods are presented here. Empathy-based stories are used to capture the contextually bound thinking of research participants. Visual methods, such as photo elicitations, employ empowering photographs, called photo voice, to reveal otherwise less obvious features of daily life and transcend the cultural barriers of participation. The voice-centred method is applied during the analytical stage of the research process to emphasise the roles of actors, both the participants and the researchers. Consultation, a non-adversarial process of synergic discussion is an instrument for determining goals at the local or national levels and the means to achieve them. Communicative research engagement is a process where researchers create a space for education dialogue to discuss and analyse a topic requiring a new solution. The draft strategy for improvement is brought to a broader stakeholder dialogue and to higher levels of the decision-making hierarchy. All incorporate those on the ground as stakeholders in the educational process.

\subsection{Empathy-based stories}

Empathy-based stories are short, imaginary writings composed by research participants as a reaction to an introductory script provided by the researcher. The method has been developed as a modification of active role-playing for the purpose of studying the subject's interpretations of situations. This form of passive role-play is used for acquiring information on the experience and ideas embedded in narratives written by individuals. (Eskola, 1998; Eskola and Kihlström, 1988; Ginsburg, 1979.) Empathy-based stories are grounded in the narrative tradition, emphasising the two-way relationship of reality and the narrative (Suoranta, 1996; Bruner, 1987) and where narratives endow experience with meaning (Bruner, 1986). Research participants are viewed as competent members of their culture with knowledge, both explicit and tacit, of the rules that guide and evaluate situated actions (Ginsburg, 1979). Essentially, empathy-based stories aim at capturing the social and cultural engagement of the situation and the respondent self (Eskola, 1998).

In the study of educational development, empathy-based stories give access to socially and culturally bound individual perspectives and thereby help to focus the research on issues that are 
relevant to the people studied. Empathy-based stories have been applied in the analysis of female students' conceptions of success in education and the social and cultural support available to female students in Tanzania (Posti-Ahokas, 2012). The introductory scripts are based on previous research and written in collaboration with Tanzanian researchers. An example of an introductory script is presented below about a young girl passing Form 5 with high grades together with two empathybased stories written by students to show how the stories generated data.

Introductory script:

Last year, Asha passed her O-level exams with good grades and she has now started her studies on Form 5. She is happy to have made it to Form 5 because her parents have made a great effort to find the money for her education. Asha thinks studying has now become more challenging and she is struggling to pass her exams this year. Her goal is to proceed all the way up to university and become a lawyer.

Try to enter to Asha’s situation and write a story on how she will manage!

Two examples of the empathy-based stories written by the students:

"Asha should first be confident that she can reach the place of her choice (her goal). Secondly, she should thoroughly seek her God by adhering to religious principals alongside observing discipline before her elders. Not only those, but she should also strive at all costs for accessing various books and other sources of education, while at the same time, trying to involve the like-minded colleagues whose goals are similar to those of hers. Again whenever she experiences difficulties, like in comprehending during lessons in class, she should ask her teachers or those fellow students at Form Six level. Lastly, Asha should be closely supported by her parents so as to reach her goals since parents are the pillar of life."

"On my side, I advise Asha to strive with her studies since she is lucky to have parents who take great initiatives with all their heart to ensure their child pursues her studies. If she has really opted for schooling, she will really study up to university - once you have stripped your clothes for the water, you have got to bathe in it. However she should avoid allurements at school since she is a female child - she should take note on those and God will help her."

Empathy-based stories are useful for obtaining rich, culturally contextualized data. The issues linked to educational attainment found in the empathy-based stories were coded and further organised into categories: A) 'personal attributes and strategies' such as confidence, accessing additional information, involving like-minded colleagues, asking teachers and senior students, being courageous, avoiding allurements; and B) 'social and cultural issues' such as peer support, parental support, abuse of female students, religion. Empathy-based stories proved to be helpful in identifying critical issues from the perspective of students.

\subsection{Visual methods: Photo elicitations, empowering photographs and photo voice}

Visual methods use the power of photography to elicit information from past and present events to build self-esteem and to act as a tool for social change. They have been used creatively in education and social science research (Emmel and Clark, 2009; Finch, 2007; Holm, 2008; Mason and Dale, 2011). Photographs were used by Kaplan and his colleagues to investigate the ethics of inclusion and exclusion (Kaplan et al., 2011). Photos can be used to create a neutral ground for the 
stimulation of discussion without leading the participants to the direction of the preconceived notions of the researcher.

Photography is often about power, who takes pictures and who is in the pictures. PhotoVoice aims to undo the power division by providing the means for people on the ground to record their community's strengths and weaknesses and enhancing dialogue with policy makers (PhotoVoice, 2009). In research this approach changes the respondents from being research objects to active research participants. In photo elicitation a photograph is inserted into a research interview (Harper, 2002). Photographs can elicit information and evoke feelings and memories that may have not emerged in the interviews without the photographs (Gold, 2004; Twine, 2006). Photographs are not analysed as primary data, but combined with the narrations of the photos.

Photo elicitation has been used in a study of immigrant women living in Finland (JanhonenAbruquah, 2010). The women showed photographs of their families and daily lives. Even though the respondents and the interviewer did not share a long history together, the photos became a catalyst in creating easy flowing conversations, as suggested by Ryen (2001). It was the photographs which stimulated discussion rather than the researcher's questions. The photograph narrations were analyzed in order to find social, modal and spatial dimensions of daily activities. The spatial dimensions formed seven units of activity settings: space for friendship, food, resting, childhood, caring, learning and an orderly space. Attention was also paid to the accommodative nature of activities, how women maintained traditions and adapted to Finnish life or created new activity patterns. The analysis showed the variety of activities in a structured way. Photos can assist educational research by conceptualizing the daily reality of people on the ground and identifying pathways to enable them to realize their own educational goals.

\subsection{Voice-centred data analysis (VCR)}

The Voice-Centred Relational (VCR) method is an analytical tool that was originally developed as a "Listener's Guide” in psychology to ask and answer three interrelated questions: "Who is speaking under what circumstances?", "Who is listening?" and "What is the nature of the listener-speaker relationship?” (Brown, 1997; Byrne et al., 2007). Literally, the voices of the participants lie at the heart of the VCR method which directs the researcher to exercise intensive listening, not only during the interviews, but also while reading and interpreting the interview transcripts. Sociologists Mauthner and Doucet (1998; 2003) have built a model based on focused readings of interview transcripts. During the first reading the researcher takes into the analysis the overall story, their own reaction to the story, including their emotional and intellectual responses and pre-conceived ideas and assumptions about the story and the people involved. The second reading is about listening to how the research participants represent themselves. The third reading traces the relationships between the research participant and the "others". Finally, the fourth reading contextualises the narrative within broader social settings and structures.

The VCR method has been applied in the research of highly educated women in Tanzania (Okkolin, 2012). It proved valuable in providing a sense of experienced and perceived agency and social location and recognized the importance of their social context. Additionally, intensive listening acknowledges the relationship between the listener and the speaker, especially in respect to power, privilege and hierarchies. It creates room for reflexion and perspectives difficult to find otherwise. The following example illustrates how the method is applied when reading and interpreting interview transcripts. 
"I decided to study business administration. Then I got the option to go to X University with a scholarship. It was free. I think it was the funding that most importantly guided my educational choices. My parents had no money, so what we did, was to take the first chance.” (Rabia)

After the initial reading, the second iteration focuses on how Rabia represents herself. When discussing educational opportunities and choices, she expressed, "I decided to study business administration". The statement shows that she perceives that she made a decision by herself concerning her study plans. The third review of the interview traces the relationship between Rabia and the others, "my parents had no money, so what we did, was to take the first chance." The fourth reading focuses on the narrative within its broader social settings and structures, "then I got the option to go to X University with a scholarship. It was free. I think it was the funding that most importantly guided my educational choices”. The final analysis shows that while it was Rabia's decision to pursue higher education it was the scholarship, that is, the wider social settings and structures providing an enabling opportunity which made the crucial difference in decision-making about her educational career. This multiperspective listening provides deeper contextualization of the educational career decision making processes.

\subsection{Consultation as a Research Tool}

Consultation is a non-adversarial process of synergic discussion applied as a methodological tool for determining goals and the means to achieve them. In education research consultation has been used at a variety of levels, from classroom to the national level (Tuomi 2001/2004; Tuomi 2005). The method was applied for the improvement of pre-service teacher training to enable student teachers to meet the inevitable new challenges in their future careers and for professional development of teachers in areas not covered by their training (Tuomi, 2004; 2005). The educational stakeholders who took part in the in consultation studies over a four year period included school principals, teachers, retired teachers, teacher trainers, social workers, researchers, parents and student teachers. The participants were trained by imagining that each of them was a NASA engineer responsible for a system vital for the survival and return of a space crew in trouble in space. The astronauts could return alive only if the solution would work from all of their perspectives, such as power, oxygen or navigation, so the contribution of every engineer/stakeholder was essential in order to bring the crew home alive.

A description of the consultation process used is depicted in Figure 1. First the question or the goal was clarified by the group. Information was gathered from a wide range of sources, seeking out diverse points of view. Where necessary, advice is sought from experts outside the group. During the discussion, participants make every effort to be as frank and candid as possible, while being open to the ideas and opinions of others. Confrontation is to be avoided; ideas conflict, rather than people. When an idea was put forth, it became the property of the group, and not of any individual. The group strives for unanimity; with an agreement that if a decision is made by a majority vote, it will be supported by all. In this way, if a result of the consultation fails, the problem is in the idea itself, rather than the lack of support from its internal opponents.

During the consultation, not only was the theme discussed, but also its implementation. A list of conclusions gleaned from the consultation is given to the stakeholders for their adjustments and approval to confirm that the conclusions truly reflect the groups' consensus. Further themes are chosen based on the previous findings. 


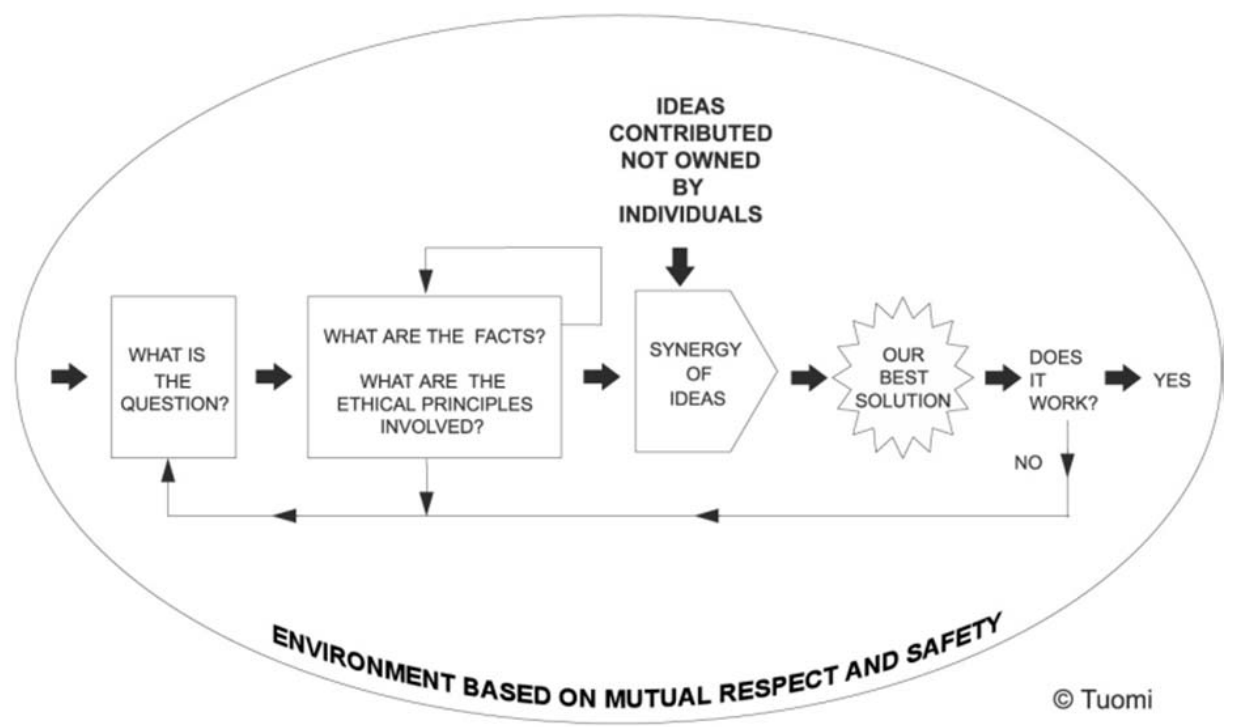

Figure 1 Description of the consultation process

A number of critical areas were identified for which there was no information available. In these areas, the stakeholders themselves became involved in the creation of that knowledge. They were able to identify areas for development in pre-service training and professional teachers' needs and take part in meeting them. Use of the consultation method involving educational stakeholders from the ground provides an opportunity to bring a variety of perspectives to the table, identifying areas requiring attentions and responding to the need (Tuomi, 2004).

\subsection{Communicative methods (research engagement in dialogue)}

In communicative research, team members engage in dialogue with the study participants and create opportunities for communicating, visualising and sharing views. Research engagement in dialogue is a process where researchers, together with study participants on the ground, discuss and analyse a topic requiring a new solution. After a consensus is reached, a draft strategy is produced and offered for a broader dialogue, among other groups of stakeholders and at a higher level of education decision-makers. A revised draft is introduced to the next level. The participatory strategy process is conducted from bottom to top, while more time and efforts are invested on the ground (Figure 2). Flecha (2011) and his research group developed the method based on Sen’s (1999) capability approach to increase educational and social inclusion.

The communicative method is applied when researchers engage in dialogue with participants in community and different levels of the education system. One example of the research engagement is the participatory process for development of a federal level special needs education strategy to promote universal primary education and Education For All process that took place in Ethiopia during 2004-2007. Information was collected from a wide range of stakeholders. The findings were analysed and discussed with the stakeholders. After further analysis a draft strategy was compiled and shared with representatives of the education authorities at different levels, universities and teacher education institutions, civil society organizations and international partners. Finally, the participatory strategy process contributed to federal government level education sector development 
plans (Ayana and Lehtomäki, 2006; UNESCO 2010; WHO 2011). One of the shortcomings of the participatory strategy design process in Ethiopia was the difficulty to reach communities at all levels, and in all corners of the vast country. Geopolitics and differences in the general decentralization process across the country challenged participation. Due to time limitations the process was made as participatory as possible.

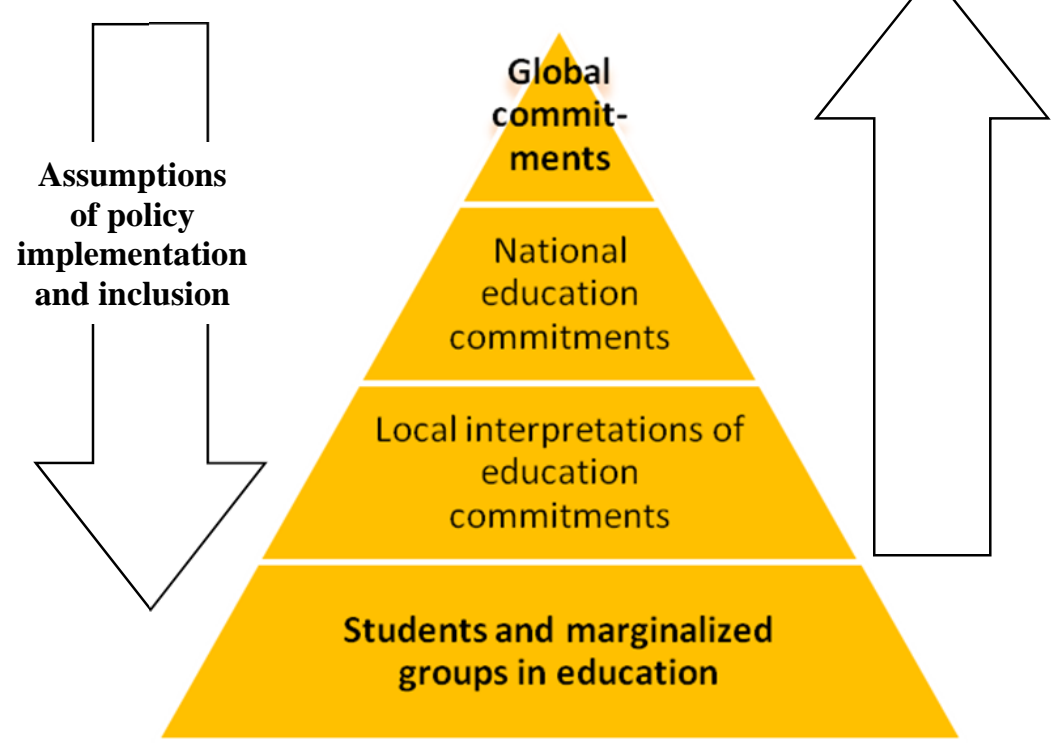

Research engagement in dialogue:

4) Sharing knowledge of the use of inclusive and participatory strategy process

3) Draft strategies in focus group dialogue $\rightarrow$ strategies

2) Solutions in focus group dialogue $\rightarrow$ joint draft strategies

1) Research engagement with students and marginalized groups $\rightarrow$ suggestions for solutions $=$ preliminary findings

Figure 2 Research engagement in dialogue: inclusive and participatory strategy process

Research engagement in dialogue is a time-consuming approach. It requires the long-term commitment of both the participants and researchers as well. Social, cultural and political power relations may pose challenges for gaining access to participants on the ground, facilitating dialogue and reporting. The approach emphasises participation for changes on the ground and the inclusion of marginalised groups in particular (Aubert, 2011; Flecha, 2011).

\section{An overview of the research methodologies to engage the voices on the ground}

In the research methods presented here, the process itself engages the voices of those on the ground, that is, people in their contexts, for enhancing the social sustainability in educational development. Engaging voices from many levels, however, does not come without difficulties. The challenges and costs of broadening the dialogue base must not outweigh the benefits. In this section we look at the strengths and weaknesses of the methodologies in relation to their potential for capturing and engaging the voices on the ground. These features are outlined in Table 1. 
Table 1 Overview of the Research Methodologies to Engage Voices in the Educational Development Dialogue

\begin{tabular}{|c|c|c|c|}
\hline Method & Characteristics & Strengths & Weaknesses \\
\hline $\begin{array}{l}\text { 1. Empathy- } \\
\text { based stories }\end{array}$ & $\begin{array}{l}\text { Respondents seen as } \\
\text { competent members of their } \\
\text { culture. They tell their stories } \\
\text { of what may happen and why. }\end{array}$ & $\begin{array}{l}\text { Effective in capturing shared } \\
\text { cultural meanings }\end{array}$ & $\begin{array}{l}\text { Does not enable } \\
\text { reliable study of } \\
\text { individual } \\
\text { experience. }\end{array}$ \\
\hline $\begin{array}{l}\text { 2. Visual } \\
\text { methods (photo } \\
\text { elicitations, } \\
\text { empowering } \\
\text { photographs, } \\
\text { photo voice) }\end{array}$ & $\begin{array}{l}\text { Power of photographs aiming } \\
\text { for personal or social change, } \\
\text { to display one's identity, see } \\
\text { reality through someone else's } \\
\text { eyes }\end{array}$ & $\begin{array}{l}\text { Reveals less obvious features } \\
\text { and transcend cultural } \\
\text { barriers, possibility to revisit } \\
\text { history }\end{array}$ & $\begin{array}{l}\text { Does not capture the } \\
\text { dynamic aspect as in } \\
\text { video recordings, } \\
\text { through whose eyes } \\
\text { do we see the } \\
\text { photographs: } \\
\text { researcher's or } \\
\text { research participant's }\end{array}$ \\
\hline $\begin{array}{l}\text { 3. Voice-centred } \\
\text { method of data } \\
\text { analysis (VCR) }\end{array}$ & $\begin{array}{l}\text { An analytical tool for } \\
\text { exercising reflexivity during } \\
\text { the interpretative stage(s) of } \\
\text { research. }\end{array}$ & $\begin{array}{l}\text { Validates interpretations by } \\
\text { incorporating reflexive } \\
\text { observations and accounts } \\
\text { explicitly in the analysis. }\end{array}$ & $\begin{array}{l}\text { A risk of over- } \\
\text { simplifying the } \\
\text { complex process of } \\
\text { voice representation. }\end{array}$ \\
\hline $\begin{array}{l}\text { 4. Consultation } \\
\text { (synergic, non- } \\
\text { confrontational } \\
\text { decision making) }\end{array}$ & $\begin{array}{l}\text { A non-adversarial process of } \\
\text { synergic discussion, to } \\
\text { identify and determine goals } \\
\text { and the means to achieve } \\
\text { them. }\end{array}$ & $\begin{array}{l}\text { Employs the collaboration of } \\
\text { all actors in research to } \\
\text { analyse and search for new } \\
\text { solutions. Can iterate until } \\
\text { solutions are found and can } \\
\text { respond to new changes. }\end{array}$ & $\begin{array}{l}\text { Time is needed to } \\
\text { establish an } \\
\text { environment of trust } \\
\text { so each involved in } \\
\text { the consultation is } \\
\text { able to contribute } \\
\text { fully to the process }\end{array}$ \\
\hline $\begin{array}{l}\text { 5.Communicative } \\
\text { methods } \\
\text { (research } \\
\text { engagement in } \\
\text { dialogue) }\end{array}$ & $\begin{array}{l}\text { Researchers take part in } \\
\text { dialogue that aims to improve } \\
\text { situation of participants and } \\
\text { share knowledge. Data } \\
\text { collected through } \\
\text { participatory observations, } \\
\text { visualizations, photography } \\
\text { and communicative focus } \\
\text { groups. }\end{array}$ & $\begin{array}{l}\text { Transparency throughout the } \\
\text { research process. Bring } \\
\text { findings back to participants. } \\
\text { Employ the collaboration of } \\
\text { stakeholders in research to } \\
\text { analyse and search for new } \\
\text { solutions. Involves } \\
\text { participants in decision- } \\
\text { making. }\end{array}$ & $\begin{array}{l}\text { Time-consuming } \\
\text { approach, requires } \\
\text { the long-term } \\
\text { commitment of both } \\
\text { the researchers and } \\
\text { the participants }\end{array}$ \\
\hline
\end{tabular}

Empathy-based stories have proved to be a methodological tool for generating rich and meaningful data on shared cultural meanings and also as a strategy to give voice to people whose voice may not otherwise be heard in research (Posti-Ahokas, 2012). Therefore, the potential of the method lies in finding new perspectives and inventing hypotheses. Photographs evoke information, feelings and memories. They clarify, emphasize and transfer powerful representations from the past to the present day. An increased use of photographs in research reflects the wider use of visual images in general and is related to the simplification of photographic technology. Further adaptations are needed to engage the research participants in the entire research process from data collection to coanalysis of the data. The VCR method is particularly valid for contextualising research data (Okkolin, 2012). There is a risk of oversimplification when representing voices and how interpretations are reached. Secondly, full awareness of all the contributing factors during the research process is not possible (Mauthner and Doucet, 2003). When exercising reflective analysis the researchers need to be aware of their own assumptions, and not consider it to be knowledge. 
Consultation requires an environment of trust among the stakeholders. A milieu is needed where each stakeholder can safely contribute to the process despite unpopular or unfamiliar perspectives. This takes time, particularly when bridging the gaps found from the micro to the macro level. The key advantage is that participating in research provides opportunities for empowerment and finding solutions to the problems people have identified through research (Anyon, 2009). At best, the communicative methods challenge existing structures. Children, adolescents and adults are actors and social agents who take part in the dialogue that aims to improve their lives. Aubert (2011) and Flecha (2011) emphasize intensifying the dialogue between the knowledge derived from the participating social agents and the international scientific community. The most challenging part of the process is the inclusion of the voices on the ground in the dialogue for defining and re-defining policies and goals and the established structures for their realization.

\section{Some considerations when engaging voices on the ground}

In education system development, a participatory approach that includes voices of the stakeholders has proven to have potential for shared values and long-term commitment (ADEA 2012; Ayana and Lehtomäki, 2006; Flecha, 2011). However, research that aims to give voice to children, youth, students and marginalized groups may also create new challenges. Unrealistic expectations may arise, and more seriously, the process may threaten the situation of the participants and the researchers. By involving participants on the ground in inquiry and giving voice to the undervalued, under-represented or marginalized groups in a society may raise ethical concerns and even increase political risks to the participants. Questions concerning data collection, the availability of the data for third parties and limitations on the use of results or other elements of the research project may be inquired (Christians, 2005). Especially the use of images may contain culturally sensitive material in addition to legal issues concerning the use of photos in public media (Clark, et al. 2010; Kaplan et al. 2011). The cultural, social and economic differences of stakeholders and researchers can challenge the interpretation and contextualization of the findings.

Education is an element of politics and researchers need to be aware of it (Christians, 2005; Lincoln, 2005). In 2012, the Association for Development of Education in Africa called for enhancing the research capacity in Africa, strengthening national ownership and enhancing the connections between local and national levels of education planning (ADEA, 2012). In their efforts to show progress towards the international benchmarks governments may undermine the "national ownership of educational policy in their drive to implement the latest development orthodoxy" (King et al., 2007, 349). Therefore, it may be difficult to convince education policy-makers that, in addition to statistics, sustainable social development requires an understanding of the so-called "target groups" in their social and cultural contexts. The inclusion of the views, interpretations, meanings and aspirations of those on the ground completes the equation. Participatory inquiry empowers persons, students, teachers and communities thereby enhancing and complementing the quantitative approach. The target groups of education development are no longer objects but subjects and participants in the research that analyses their education and learning, so fundamental for their future and the situation in general on the ground.

In practical terms, actor-centred methods and participatory action research require the long-term involvement and commitment of all the stakeholders. Consequently, the inquiry processes take time, while educational outcomes emerge gradually. Appraisals and evaluations of immediate results seldom succeed in taking into consideration long-term societal impacts. While producing short-term results the methods presented here emphasise the long-term effects. Actor-centred methods, for example, give participants tools for grasping the context-dependent nature of their educational choices in the demanding transition phases (Janhonen-Abruquah, 2010; Okkolin, 2012; 
Posti-Ahokas, 2012). In the process of consultation inquiry and communicative research engagement each phase of the research means change and, depending on the participants' views, development (Ayana and Lehtomäki, 2006; Tuomi, 2004). While this takes time, the results can be more sustainable and robust because the solutions have taken into consideration not only the global benchmarks but also, and most importantly, the situation on the ground. An example of the lack of the stakeholder engagement is found in the policies of some international agencies and income-rich countries which have guided the educational development in Sub-Saharan Africa, and ignored the existing community-level and indigenous knowledge (Breidlid, 2009; Preece 2013).

The latest European Report on Development (ERD, 2010) which discusses poverty, inequality, vulnerability and social protection with a focus on Sub-Saharan Africa, one of the most challenging areas in educational development and international cooperation proves this point. The report was produced through the collaborative efforts of promising, young, African scholars and their European counterparts and the sustained dialogue between researchers and other stakeholders (ERD, 2010). It provides the European Community, and the international community in general, with African interpretations of their current societal challenges, contextualized case studies and solutions for these processes. These results in social protection are based on a mixed-methods approach, so essential in educational development.

\section{Conclusions}

This paper is part of the on-going discussion on the role of research in the field of international education and development and contributes to broadening approaches and methodological traditions, as suggested by McGrath (2013). Promoting the use of research methods by which the stakeholders' voices are included in the educational development dialogue adds valuable insights gleaned from qualitative research to the generally descriptive reports on changes, contextualizes educational development and enhances stakeholder involvement. Therefore, the more critically contextualized our knowledge and social understanding is, the better the real questions on the ground can be addressed. Issues such as marginalization, exclusion, high dropout rates and school curricula with low relevance require collaboration. Persons with a voice actively taking part and searching for solutions within their cultural and social contexts, form the basis for a successful Education For All (EFA) process and achievement of the Millennium Development Goals. Therefore, the stakeholders on the ground are essential not only for the realization of the readymade goals, but in the dialogue on the significance of the findings and, certainly, on the modifications or changes needed in the targets. The actor-centred methods and participatory action research methodologies presented here enable the, so-called, "target groups" of the EFA and MDGs to become engaged in the dialogue by bringing their cultural and social knowledge into the processes, from planning to evaluation. Furthermore, their voices are the factors needed in the redefinition of global, national and local educational development targets for EFA beyond 2015. Dialogical development enhances the ownership of education policy and implementation.

\section{Acknowledgements}

The authors of this paper would like to thank Professor Fred Dervin, Department of Teacher Education, University of Helsinki, for his comments on a preliminary version of the manuscript. 
Research to engage...

\section{References}

ADEA, 2012. Association for Development of Education in Africa. Triennale 'Promoting Critical Knowledge, Skills and Qualifications for sustainable development in Africa: How to design and implement an effective response by education and training systems'. www.adeanet.org

Amundsen, C., Wilson, M., 2012. Are we asking the right questions? A conceptual review of the educational development literature in higher education. Review of Educational Research, 82 (1), 90-126.

Anyon, J., 2009. Introduction: Critical social theory, educational research, and intellectual agency. In Anyon, J., Dumas, M., Linville, D., Nolan, K., Perez, M., Tuck, E., Weiss, J. (Eds.), Theory and Educational Research: Toward Critical Social Explanation. New York: Routledge, pp. 1-23.

Aubert, A., 2011. Moving beyond social exclusion through dialogue. International Studies in Sociology of Education, Special Issue: Education for Social Inclusion, 21 (1), 63-75.

Ayana, A., Lehtomäki, E., 2006. Including special needs education services in the federal level education sector development program in Ethiopia: Process, strategic priorities and implications. In: Savolainen, H., Matero, M, Kokkala, H. (Eds.), When Education For All Means All: Experiences in Three African Countries with EFA and Children with Disabilities. (pp. 69-82). Ministry for Foreign Affairs. Finland. Development Policy Information Unit. Elements for Discussion. (http://www.formin.fi/public)

Breidlid, A., 2009. Culture, indigenous knowledge systems and sustainable development: A critical view of education in an African context. International Journal of Educational Development, 29 (2), 140-148.

Brown, L.M., 1997. Performing feminities: listening to white working-class girls in rural Maine. Journal of Social Issues 53, 683-701.

Bruner, J. S., 1987. Life as Narrative. Social Research, 54 (1), 11-32.

Bruner, J. S., 1986. Actual Minds, Possible Worlds. Cambridge, MA: Harvard University Press.

Byrne, A., Canavan, J., Millar, M., 2007. Participatory research and the voice-centered relational method of data analysis: is it worth it? International Journal of Social Research Methodology, 12 (1), 67-77.

Clark, A., Prosser, J., Wiles, R., 2010. Ethical issues in image-based research. Arts and Health, 2 (1), 81-93.

Christians, C.G., 2005. Ethics and Politics in qualitative research. In N.K. Denzin, Y.S. Lincoln (eds.) The SAGE Handbook of Qualitative Research (third edition). Thousand Oaks, CA: Sage, pp. 139-164.

Crossley, M., 2008. Bridging cultures and traditions for educational and international development: comparative research, dialogue and difference. International Journal of Comparative Education, 51 (34), 319-336.

Crossley, M., Watson, K., 2011. Comparative and international education: policy transfer, context sensitivity and professional development. In Furlong, J., Lawn, M. (Eds.) Disciplines of Education, their role in the future of education research. London: Routledge, pp. 103-121.

Emmel, N., Clark, A., 2009. The Methods Used in Connected Lives: Investigating Networks, Neighbourhoods and Communities. NCRM Working Paper. National Centre for Research Methods.

Eskola, A., Kihlström, A., 1988. Blind Alleys in Social Psychology: A Search for Ways Out. Amsterdam: North-Holland.

Eskola, J., 1998. Eläytymismenetelmä sosiaalitutkimuksen tiedonhankintamenetelmänä [The Method of Empathy-Based Stories as a Method of Acquiring Data in Social Research]. Tampere University. Tampere: TAJU.

ERD, 2010. The European Report on Development. Social Protection for Inclusive Development. European University Institute, Mobilising European Research for Development Policies. http://erd.eui.eu/about$2 /$.

Finch, J., 2007. Displaying families. Sociology, 41 (1), 65-81.

Flecha, R., 2011. The dialogic sociology of education. International Studies in Sociology of Education, Special Issue: Education for Social Inclusion, 21 (1), 7-20.

Foster, J., Addy, N.A., Samoff, J., 2012. Crossing borders: Research in comparative and international education. International Journal of Educational Development, 32, 711-732.

Ginsburg, G. P., 1979. The effective use of role-playing in social psychological research. In G.P. Ginsburg (Ed.) Emerging Strategies in Social Psychological Research (pp. 117-154). Chichester: Wiley.

Gold, S. J., 2004. Using photography in studies of immigrant communities. The American Behavioral Scientist. ABI/INFORM Global. 47 (12), 1551-1571.

Harper, D., 2002. Talking about pictures: a case for photo elicitation. Visual Studies, 17 (1), 13-26. 
Holm, G., 2008.Visual research methods: where are we and where are we going? In S. Hesse-Biber, P. Leavy (Eds.), Handbook of Emergent Methods. Guilford, pp. 325-341.

Janhonen-Abruquah, H., 2010. Gone with the Wind? Immigrant Women and Transnational Everyday Life in Finland. Home Economics and Craft Studies Research Reports 24. Helsinki: University of Helsinki.

Kaplan, I., Miles, S., Howes, A., 2011. Images and the ethics of inclusion and exclusion: learning through participatory photography in education. Journal of Research in Special Educational Needs, 11 (3), 195-202.

King, K., McGrath, S., Rose, P., 2007. Beyond the basics: educating and training out of poverty. International Journal of Educational Development, 27 (4), 349-357.

Lincoln, Y.S., 2005. Institutional review boards and methodological conservatism: The challenge to and from phenomenological paradigms. In N.K. Denzin, Y.S. Lincoln (eds.) The SAGE handbook of qualitative research (third edition). Thousand Oaks, CA: Sage, pp. 165-182.

Little, A.W., Green, A., 2009. Successful globalisation, education and sustainable development. International Journal of Educational Development, 29 (2), 166-174.

Mason, J., Dale, A., 2011. Understanding Social Research: Thinking creatively about Method. London: Sage.

Mauthner, N., Douchet, A. 2003. Reflexive accounts and accounts of reflexivity in qualitative data analysis. Sociology, 37 (3), 412-431.

Mauther, N., Doucet, A., 1998. Reflections on a voice-centred relational method: analysing maternal and domestic voices. In Ribbens, J., Edwards, R. (Eds.), Feminist Dilemmas in Qualitative Research, Public Knowledge and Private Lives. London: Sage. pp. 119-146.

McGrath, S., 2010. Education and development: thirty years of continuity and change. International Journal of Educational Development 30 (6), 537-543.

McGrath, S., 2013. The weight and breadth of evidence: Some reflections on the strengths of international education and development research. International Journal of Educational Development, 33 (1), 1.

Okkolin, M-A., 2012. Highly Educated Women in Tanzania: Opportunities and Constraints for Constructing Educational Agency. Manuscript in preparation.

Okkolin, M-A., Lehtomäki, E., Bhalalusesa, E., 2010. Successful education sector development in Tanzania: comment on gender-balance and inclusive education. Gender and Education, 22 (1), 63-71.

PhotoVoice. 2009. http://www.photovoice.org

Posti-Ahokas, H., 2012, accepted. Empathy-based stories capturing the voice of female secondary school students in Tanzania. International Journal of Qualitative Studies in Education.

Preece, J., 2013. Africa and international policy making for lifelong learning: textual revelations. International Journal of Educational Development, 33 (1), 98-105.

Ryen, A., 2001. Cross-cultural interviewing. In Gubrium, J.F., Holstein, J.A. (Eds.), Handbook of Interview Research. Context and Method. Thousand Oaks, CA.: Sage, pp. 335-349.

Sen, A., 1999. Development as Freedom. New York: Knopf.

Suoranta, J., 1996. Kontekstualismi kasvatustieteiden metodologiassa [Contextualism in the methodology of educational sciences]. Kasvatus 27, (5), 451-462.

Tuomi, M.T., 2005. Agents of social change in education. Community Development Journal, 40 (2), 205211.

Tuomi, M.T., 2004. Planning teachers’ professional development for global education. Journal of Intercultural Education, 15 (3), 295-306.

Tuomi, M.T., 2001/2004. Human Dignity in the Learning Environment: Testing a Sociological Paradigm for a Diversity-Positive Milieu with School Starters, third ed. University of Jyväskylä. Institute for Educational Research. Research Reports 10.

Twine, F.W., 2006. Visual ethnography and racial theory: family photographs as archives of interracial intimacies. Ethnic and Racial Studies, 29 (3), 487-511.

UNESCO, 2010. EFA (Education For All) Global Monitoring Report: Reaching the Marginalized.

WHO, 2011. World Report on Disability. http://www.who.int/disabilities/world_report/2011/report/en/ 